OPEN ACCESS

Edited by:

Lee Mark Wetzler,

Boston University School of

Medicine, USA

Reviewed by:

Paola Massari,

Tufts University School of Medicine, USA

Arun Kumar,

Health Sciences North, Canada

William K. Decker,

Baylor College of Medicine, USA

${ }^{*}$ Correspondence:

Constantino López-Macías constantino@sminmunologia.mx, constantino.lopez@imss.gob.mx

Specialty section:

This article was submitted to Vaccines and Molecular

Therapeutics,

a section of the journal

Frontiers in Immunology

Received: 23 December 2016 Accepted: 17 February 2017

Published: 09 March 2017

Citation:

Pérez-Toledo M, Valero-Pacheco N,

Pastelin-Palacios R, Gil-Cruz C,

Perez-Shibayama C,

Moreno-Eutimio MA, Becker I,

Pérez-Tapia SM, Arriaga-Pizano L,

Cunningham AF, Isibasi A, Bonifaz LC

and López-Macías C (2017)

Salmonella Typhi Porins OmpC

and $\mathrm{OmpF}$ Are Potent Adjuvants

for T-Dependent and

T-Independent Antigens.

Front. Immunol. 8:230.

doi: 10.3389/fimmu.2017.00230

\section{Salmonella Typhi Porins OmpC and OmpF Are Potent Adjuvants for T-Dependent and T-Independent Antigens}

\author{
Marisol Pérez-Toledo ${ }^{1,2}$, Nuriban Valero-Pacheco, ${ }^{1,2}$,Rodolfo Pastelin-Palacios ${ }^{3}$, \\ Cristina Gil-Cruz ${ }^{4}$, Christian Perez-Shibayama ${ }^{4}$, Mario A. Moreno-Eutimio ${ }^{5}$, \\ Ingeborg Becker, Sonia Mayra Pérez-Tapia ${ }^{7}$, Lourdes Arriaga-Pizano', \\ Adam F. Cunningham ${ }^{8}$, Armando Isibasi ${ }^{1}$, Laura C. Bonifaz ${ }^{1}$ and \\ Constantino López-Macías ${ }^{1,9 *}$
}

\begin{abstract}
'Medical Research Unit on Immunochemistry, Specialties Hospital, National Medical Centre "Siglo XXI", Mexican Social Security Institute, Mexico City, Mexico, ${ }^{2}$ Departamento de Inmunología, Escuela Nacional de Ciencias Biológicas, Instituto Politécnico Nacional, Mexico City, Mexico, ${ }^{3}$ Facultad de Química, Universidad Nacional Autónoma de México, Mexico City, Mexico, ${ }^{4}$ Institute of Immunobiology, Kantonsspital St. Gallen, St. Gallen, Switzerland, ${ }^{5}$ Immunity and Inflammation Research Unit, Hospital Juárez de México, Ministry of Health, Mexico City, Mexico, ${ }^{6}$ Facultad de Medicina, Departamento de Medicina Experimental, Universidad Nacional Autónoma de México, Mexico City, Mexico, ${ }^{7}$ Unit of R\&D in Bioprocesses (UDIBI), Department of Immunology, National School of Biological Sciences, National Polytechnic Institute, Mexico City, Mexico, ${ }^{8}$ MRC Centre for Immune Regulation, College of Medical and Dental Sciences, Institute of Immunology and Immunotherapy, University of Birmingham, Birmingham, UK, ${ }^{9}$ Nuffield Department of Medicine, University of Oxford, Oxford, UK
\end{abstract}

Several microbial components, such as bacterial DNA and flagellin, have been used as experimental vaccine adjuvants because of their inherent capacity to efficiently activate innate immune responses. Likewise, our previous work has shown that the major Salmonella Typhi (S. Typhi) outer membrane proteins OmpC and OmpF (porins) are highly immunogenic protective antigens that efficiently stimulate innate and adaptive immune responses in the absence of exogenous adjuvants. Moreover, S. Typhi porins induce the expression of costimulatory molecules on antigen-presenting cells through toll-like receptor canonical signaling pathways. However, the potential of major $S$. Typhi porins to be used as vaccine adjuvants remains unknown. Here, we evaluated the adjuvant properties of $S$. Typhi porins against a range of experimental and clinically relevant antigens. Co-immunization of $S$. Typhi porins with ovalbumin (OVA), an otherwise poorly immunogenic antigen, enhanced anti-OVA IgG titers, antibody class switching, and affinity maturation. This adjuvant effect was dependent on CD4+ T-cell cooperation and was associated with an increase in IFN- $\gamma, \mathrm{IL}-17 \mathrm{~A}$, and IL-2 production by OVA-specific CD4+ $T$ cells. Furthermore, co-immunization of $S$. Typhi porins with an inactivated H1N1 2009 pandemic influenza virus experimental vaccine elicited higher hemagglutinating anti-influenza IgG titers, antibody class switching, and affinity maturation. Unexpectedly, co-administration of $S$. Typhi porins with purified, unconjugated Vi

Abbreviations: OMP, outer membrane protein; iIAV, inactivated influenza A virus; PorK, proteinase K digested porins; HAU, hemagglutinating units; GLA-SE, glucopyranosyl lipid adjuvant-stable emulsion. 
capsular polysaccharide vaccine (Vi CPS) - a T-independent antigen-induced higher IgG antibody titers and class switching. Together, our results suggest that $S$. Typhi porins OmpC and OmpF are versatile vaccine adjuvants, which could be used to enhance T-cell immune responses toward a Th1/Th17 profile, while improving antibody responses to otherwise poorly immunogenic T-dependent and T-independent antigens.

Keywords: porins, adjuvants, influenza, Vi polysaccharide, IFN-gamma, IL-17, antibody responses

\section{INTRODUCTION}

Numerous microbial components, such as CpG and flagellin, are pathogen-associated molecular patterns (PAMPs) that have been used as experimental vaccine adjuvants. Such activities reflect their capacity to activate innate immune responses through pattern recognition receptors, such as toll-like receptors (TLRs) (1). In addition to these PAMPs, the outer membrane proteins (OMPs, porins) of Gram-negative bacteria have also been shown to efficiently activate innate immune responses $(2,3)$. Porins are transport channels that play a key role in the diffusion of small molecules and in bacterial homeostasis (4). Numerous groups have studied the effects of porins from Neisseria (5), Haemophilus (6), Pasteurella (7), Fusobacterium (8), Shigella $(9,10)$, and Salmonella (11-14) on the activation of antigen-presenting cells (APCs). Because of the known effects that bacterial porins can have on the activation of APCs, some of these proteins have been used as potential vaccine adjuvants $(5,8,13-15)$. The mechanism underlying the adjuvant effect of these porins includes events involving both innate and adaptive cells. For example, the adjuvant effect of PorB porin from Neisseria meningitidis is associated with the upregulation of costimulatory molecules and induction of lymphocyte proliferation, MHC-II overexpression, and secretion of proinflammatory cytokines by APCs, mediated mainly by TLR $2 / 1$ ligation (15-18).

Salmonella Typhi expresses multiple porins (19-21). While the major $S$. Typhi OmpC and OmpF porins are expressed constitutively, other porins, such as OmpS1 and OmpS2, are expressed at low levels under in vitro culture conditions and potentially during infection $(22,23)$. We have previously shown that the major and minor $S$. Typhi porins are highly immunogenic antigens and drive robust responses in the absence of exogenous adjuvants (14,24-28). The major and minor $S$. Typhi porins can efficiently activate the innate immune system through canonical TLR2 and TLR4 signaling, resulting in increased costimulatory molecules and cytokine expression on dendritic cells (DCs) and B cells $(12,14)$.

Here, we evaluated the potential of the major $S$. Typhi porins to have an adjuvant effect against three distinct types of antigens, including ovalbumin (OVA) (a model antigen), an inactivated H1N1 2009 pandemic influenza virus, and a Vi polysaccharide, T-independent vaccine. These data show that porins promoted responses to all three antigens, indicating that these proteins may be used as adjuvants to a range of different types of antigens.

\section{MATERIALS AND METHODS}

\section{Ethics Statement}

All animal procedures were conducted in accordance with national guidelines (Norma Oficial Mexicana, NOM-062-ZOO 1999), following review and approval by the Specialties Hospital Ethics Committee of Instituto Mexicano del Seguro Social (IMSS) (project number CNIC 2006-785-076).

\section{Antigens and Immunogens}

Endotoxin-free OVA was purchased from Seikagaku Corp. (Tokyo, Japan). Pandemic influenza virus (strain A/ Mexico/4482/2009(H1N1)) was grown in chicken embryos and kindly provided by the Instituto Nacional de Diagnóstico y Referencia Epidemiológicos (InDRE), Mexico City. The virus was inactivated using formalin [inactivated influenza A virus (iIAV)] and quantified by hemagglutination. For ELISA assays, iIAV was concentrated with $6 \%$ polyethylene glycol 8000 (Sigma, MO, USA) and further purified by centrifugation in a $20-60 \%$ sucrose density-gradient in NTE Buffer [ $100 \mathrm{mM} \mathrm{NaCl}, 10 \mathrm{mM}$ Tris-Cl ( $\mathrm{pH}=7.4), 1 \mathrm{mM}$ EDTA] as described elsewhere (29), and protein content was quantified by the bicinchoninic acid method.

Porins were purified from S. Typhi ATCC 9993 as previously described $(12,27)$. LPS content was measured using the limulus amebocyte lysate assay (Endosafe ${ }^{\circledR}$ KTA; Charles River Endosafe Laboratories, Charleston, SC, USA), and all batches tested negative (detection limit, $0.01 \mathrm{ng}$ LPS $/ 10 \mu \mathrm{g}$ protein). Digested porins (PorK) were prepared with $10 \mu \mathrm{g}$ of proteinase K (New England Biolabs, MA, USA) per $30 \mu \mathrm{g}$ of porins, followed by overnight incubation at $37^{\circ} \mathrm{C}$ and inactivation of the enzyme at $70^{\circ} \mathrm{C}$ for $1 \mathrm{~h}$. LPS from Escherichia coli 0111:B4 was purchased from Sigma (MO, USA). Rehydragel was used as an alum control (Reheis, NJ, USA). Typhim Vi vaccine was obtained from Sanofi Pasteur (Lyon, France).

\section{Mice}

Male BALB/c mice (6- to 8-week olds) were purchased from Harlan Laboratories (Mexico City, México). DO.11.10 mice $\mathrm{OVA}_{323-339}$ transgenic mice were bred at the animal facilities of the Experimental Medicine Department, Faculty of Medicine, Universidad Nacional Autónoma de México (UNAM).

\section{Immunization Protocol}

$\mathrm{BALB} / \mathrm{c}$ mice were immunized i.p. with $100 \mu \mathrm{g}$ of OVA, 4 hemagglutinating units (HAU) of iIAV alone or with $10 \mu \mathrm{g}$ of major $S$. Typhi porins, $10 \mu \mathrm{g}$ of proteinase $\mathrm{K}$ digested porins, $5 \mu \mathrm{g}$ of 
LPS, or $100 \mu \mathrm{g}$ alum. Animals were boosted on day 15, and blood samples were taken at the indicated time points. For Vi CPS experiments, mice were immunized i.p. with $10 \mu \mathrm{g}$ of Typhim Vi CPS vaccine alone or with $10 \mu \mathrm{g}$ of $S$. Typhi porins, or proteinase $\mathrm{K}$ digested porins, with a boost on day 15 .

\section{Adoptive Transfer and Assessment of T Cell Response}

A total of $5 \times 10^{6}$ CFSE-labeled CD4 ${ }^{+} \mathrm{T}$ cells from DO.11.10 mice were adoptively transferred i.v. After $24 \mathrm{~h}$, mice were immunized s.c. in the footpads. Three days after immunization, the popliteal lymph nodes were extracted and $\mathrm{CD} 4^{+} \mathrm{T}$ cells were purified by negative selection with Dynabeads ${ }^{\circledR}$ (Thermo Fisher Scientific, MA, USA). To assess in vivo T-cell proliferation, $\mathrm{CD}^{+}$ $\mathrm{T}$ cells were stained with PE-conjugated KJ1-26 mAb (against DO.11.10 transgenic TCR) and APC-conjugated anti-CD4 (BD Biosciences, CA, USA). To determine the cytokine production, $\mathrm{CD}^{+} \mathrm{T}$ cells were cocultured at a ratio of 3:1 with splenic DCs purified by positive selection from naïve mice. DCs were used alone or pulsed with $100 \mu \mathrm{g}$ of OVA. Then, $24 \mathrm{~h}$ after stimulation, the supernatants were collected, and the cytokines were quantified using a Th1/Th2/Th17 CBA kit following the manufacturer's instructions (BD Biosciences, CA, USA). Data were acquired on a FACSCalibur (Becton-Dickinson, NJ, USA) and analyzed using FlowJo 7.5 software (Tree Star, Stanford, CA, USA).

\section{Antibody ELISA}

High-binding, 96-well polystyrene flat bottom plates (Corning, NY, USA) were coated with $15 \mu \mathrm{g}$ of OVA (Sigma, USA), $1 \mu \mathrm{g}$ of iIAV or $1 \mu \mathrm{g}$ of Typhim Vi vaccine per well, each dissolved in $0.1 \mathrm{M}$ carbonate buffer ( $\mathrm{pH}$ 9.5). Non-specific binding was blocked with $5 \%$ non-fat dry milk diluted in $\mathrm{PBS} \mathrm{pH} \mathrm{7.2.} \mathrm{Sera} \mathrm{were}$ serially diluted twofold and incubated for $1 \mathrm{~h}$ at $37^{\circ} \mathrm{C}$. Peroxidaseconjugated anti-mouse IgM, IgG H + L, IgG2a, IgG2b, or IgG3 (Invitrogen, CA, USA) were diluted at a ratio of 1:1,000. The plates were developed with $0.5 \mathrm{mg} / \mathrm{mL}$ ortho-phenylenediamine (Sigma, MO, USA) in $0.1 \mathrm{M}$ citrate buffer ( $\mathrm{pH}$ 5.6) containing $0.08 \% \mathrm{H}_{2} \mathrm{O}_{2}$ (Sigma, MO, USA). The reaction was stopped with $1.25 \mathrm{M} \mathrm{H}_{2} \mathrm{SO}_{4}$, and the optical densities were read at $492 \mathrm{~nm}$ using an automatic ELISA plate reader (Multiskan Ascent, Thermo Scientific, Vantaa, Finland). The cutoff value was defined as threefold above the mean values of the negative controls.

High-avidity IgG antibodies were measured including a wash with a mild-denaturing agent to discriminate low-avidity antibodies, which are more likely to dissociate from the antigen-antibody complexes (30). Briefly, ELISA was performed as described above including a $10 \mathrm{~min}$ wash with $7 \mathrm{M}$ urea solution after incubation of sera and before the addition of the secondary antibody.

\section{Hemagglutination Inhibition Assay}

Sera were treated with receptor destroying enzyme (Denka Seiken, Tokyo, Japan) for $19 \mathrm{~h}$ at $37^{\circ} \mathrm{C}$, according to the manufacturer's instructions. Sera were serially diluted twofold in PBS using V-bottom plates (Nunc, Roskilde, Denmark). Diluted sera were incubated $30 \mathrm{~min}$ at RT with $8 \mathrm{HAU} / 25 \mu \mathrm{L}$ of a pandemic influenza virus strain A/México/4482/2009 (H1N1). After incubation, $0.5 \%$ of chicken red blood cells were added to the plates and incubated $30 \mathrm{~min}$ at RT. The hemagglutination inhibition titer was established as the highest dilution of sera where hemagglutination was completely inhibited.

\section{Statistical Analysis}

Statistical analysis was performed with GraphPad Prism 6.0 (GraphPad Software, La Jolla, CA, USA) applying one-way analysis of variance test with Bonferroni's multiple comparison correction. $P$-values $<0.05$ were considered significant. Significant differences are depicted as ${ }^{\star} P<0.05,{ }^{* *} P<0.01$, and ${ }^{* *} P<0.001$.

\section{RESULTS}

\section{OmpC and OmpF from S. Typhi Are Effective Adjuvants for Promoting Antibody Responses to OVA}

To evaluate if major $S$. Typhi porins, hereafter referred to as porins, had an adjuvant effect on OVA antibody responses, we immunized $\mathrm{BALB} / \mathrm{c}$ mice with OVA, OVA + porins, or OVA + proteinase $\mathrm{K}$ digested porins (PorK). Additionally, we included two groups immunized with OVA + alum and OVA + LPS to compare the relative effects of major $S$. Typhi porins to other known adjuvants. OVA-specific antibody titers were measured at different time points after immunization. OVA + porins induced higher IgG antibody titers, which remained detectable up to 120 days after immunization (Figure 1A), while OVA + PorK did not show an effect over OVA alone. The antibody titers induced by OVA + porins were similar to the levels induced by OVA + alum or OVA + LPS.

Next, we evaluated the affinity maturation and antibody class switching induced by co-immunization with $S$. Typhi porins at day 30 p.i. OVA + porins induced high-avidity antibodies compared to OVA alone (Figure 1B). Moreover, OVA + porins induced a significant response of IgG1, IgG2a, and IgG2b; the responses were abrogated when digested porins were used (Figure 1C). Antibody class switching and antibody titers induced by porins co-immunization were comparable to alum or LPS (Figure 1C).

Because $\mathrm{CD}^{+} \mathrm{T}$ cells cooperate with B cells to promote antibody responses (31), we investigated whether the adjuvant effect of $S$. Typhi porins was dependent on $\mathrm{CD} 4^{+} \mathrm{T}$ cells. Depletion of $\mathrm{CD} 4^{+} \mathrm{T}$ cells resulted in the complete abrogation of the antibody responses to OVA in the $S$. Typhi porins co-immunized group (Figure 1D), suggesting that $\mathrm{CD}^{+} \mathrm{T}$ cells are necessary for the adjuvant effect induced by $S$. Typhi porins on the antibody responses to OVA.

Altogether, these results suggest that $S$. Typhi porins can promote antibody responses to poorly immunogenic model antigens such as OVA, in a manner dependent on $\mathrm{CD}^{+} \mathrm{T}$ cell cooperation.

\section{S. Typhi Porins Can Increase OVA-Specific $\mathrm{CD4}^{+} \mathrm{T}$ Cell Proliferation and Th1/Th17 Cytokine Production}

Because we observed that the adjuvant effect of $S$. Typhi porins on antibody responses to OVA was dependent on $\mathrm{CD}^{+} \mathrm{T}$ cells, we examined if $S$. Typhi porins could also have an effect on OVAspecific $\mathrm{CD}^{+}{ }^{+} \mathrm{T}$ cells. $\mathrm{CD} 4^{+} \mathrm{T}$ cells from DO.11.10 mice were 


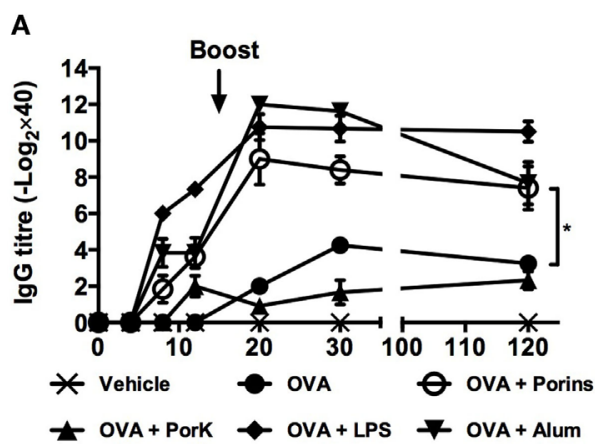

C

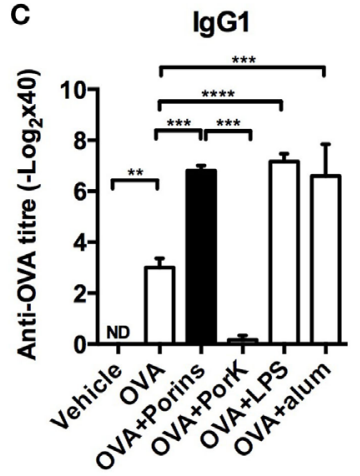

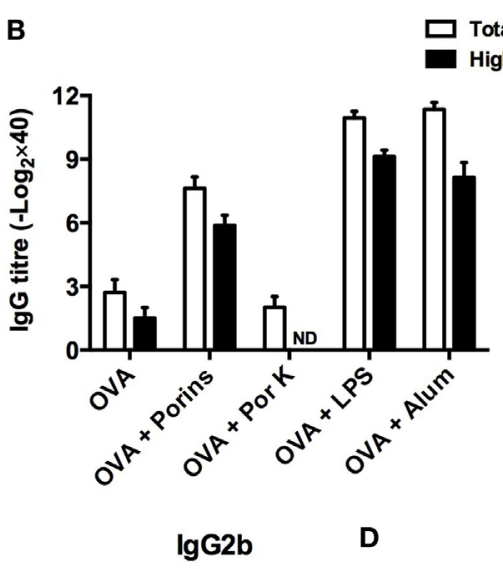
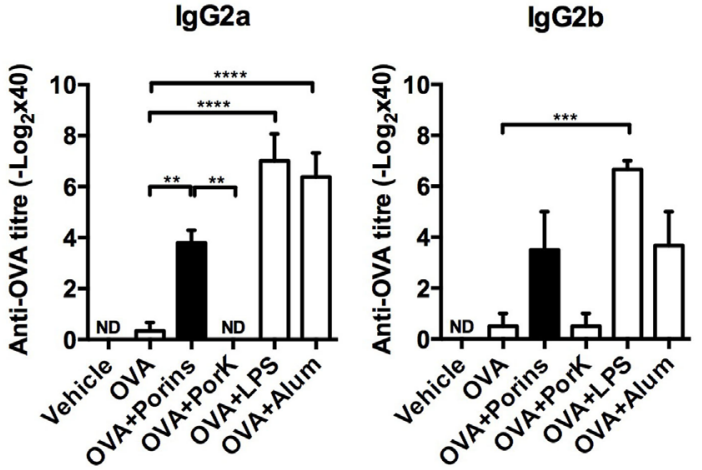

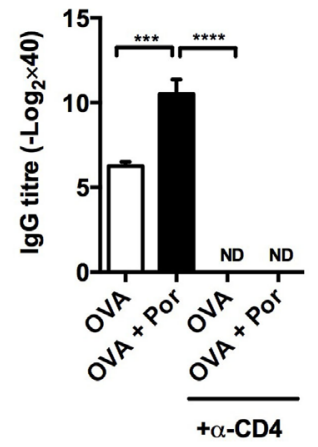

FIGURE 1 | OmpC and OmpF from S. Typhi promote antibody responses to ovalbumin (OVA). Four BALB/c mice per group were immunized i.p. with $100 \mu \mathrm{g}$ of OVA, OVA $+10 \mu \mathrm{g}$ of porins, OVA $+10 \mu \mathrm{g}$ of PorK, OVA $+5 \mu \mathrm{g}$ of LPS, or OVA $+100 \mu \mathrm{g}$ of alum. (A) Total lgG antibody responses were measured at the indicated time points by ELISA (B) high-avidity IgG and (C) IgG1, IgG2a, and IgG2b were measured at day 30 post-immunization. (D) BALB/c mice were injected i.p. with a depleting anti-CD4 mAb (GK1.5) 3 days prior to immunization with OVA or OVA + porins. GK1.5 mAb was given every 3 days thereafter until day 20, and the serum IgG and IgM responses were measured by ELISA. Mean + SEM are shown. These data are representative of three independent experiments. Statistical analysis was performed using one-way ANOVA with Bonferroni test post hoc. For panel (A), Student's $t$-test was performed comparing only OVA versus OVA + porins groups. Statistical differences are depicted as ${ }^{\star} P<0.05,{ }^{\star \star} P<0.01,{ }^{\star \star \star} P<0.001$.

CFSE labeled and adoptively transferred prior to immunization with OVA plus the different adjuvants. We found enhanced OVAspecific $\mathrm{CD}^{+} \mathrm{T}$ cell proliferation in the OVA + porins group, similar to alum or LPS (Figures 2A,B). In contrast, enhanced T cell proliferation was not observed with OVA + PorK. Assessment of cytokines produced by $\mathrm{CD} 4^{+} \mathrm{T}$ cells after $S$. Typhi porins coimmunization with OVA showed an increase in IFN- $\gamma$, IL-17A, and IL-2 (Figure 2C). Indeed, IFN- $\gamma$ and IL-17A were highest in the OVA + porins group, while the OVA and OVA + PorK groups had similar cytokine profiles. These results show that $S$. Typhi porins enhance OVA-specific $\mathrm{CD} 4^{+} \mathrm{T}$-cell proliferation as well as IFN- $\gamma$, IL-17A, and IL-2 production.

\section{S. Typhi Porins Promote Antibody Responses to Inactivated 2009 Pandemic Influenza Virus}

To evaluate if $S$. Typhi porins could improve the immune response to an experimental vaccine, we co-immunized mice with an inactivated pandemic influenza $\mathrm{A}(\mathrm{H} 1 \mathrm{~N} 1)$ virus (iIAV) plus $S$. Typhi porins, and we measured the antibody responses against influenza virus. We found that the addition of porins increased IgG antibody titers to iIAV, to a similar extent as alum or LPS, and that the response was maintained up to 120 days post-immunization (Figure 3A), with IgG1 being the most readily detectable isotype (Figure $3 \mathbf{B}$ ). Additionally, we found an increase in high-avidity IgG titers (Figure 3C). A key element of any vaccine response is to enhance the protection afforded by immunization. Therefore, we examined the ability of the induced antibodies to promote agglutination of the virus. We found that the iIAV + porins group had higher titers of anti-hemagglutinin antibodies (Figure 3D) compared to iIAV and iIAV + alum and similar levels to the iIAV + LPS group. Together, these results show that $S$. Typhi porins can potentiate functional antibody responses to an experimental pathogenderived vaccine.

\section{S. Typhi Porins Promote Antibody Responses to the T-Independent Anti-Typhoid Vi Antigen}

Because porins can induce T-dependent and T-independent responses (32), we examined if they could improve the immune response to a T-independent type 2 (TI-2) vaccine antigen. Mice 

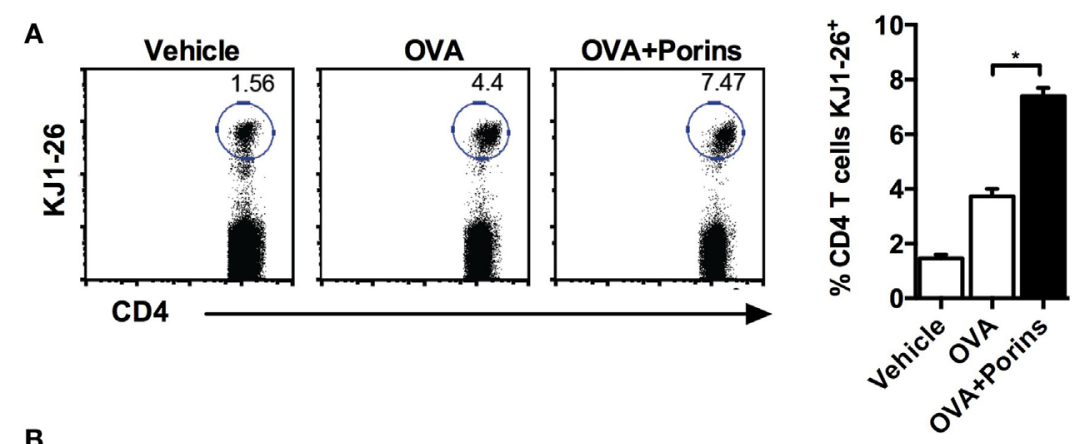

B
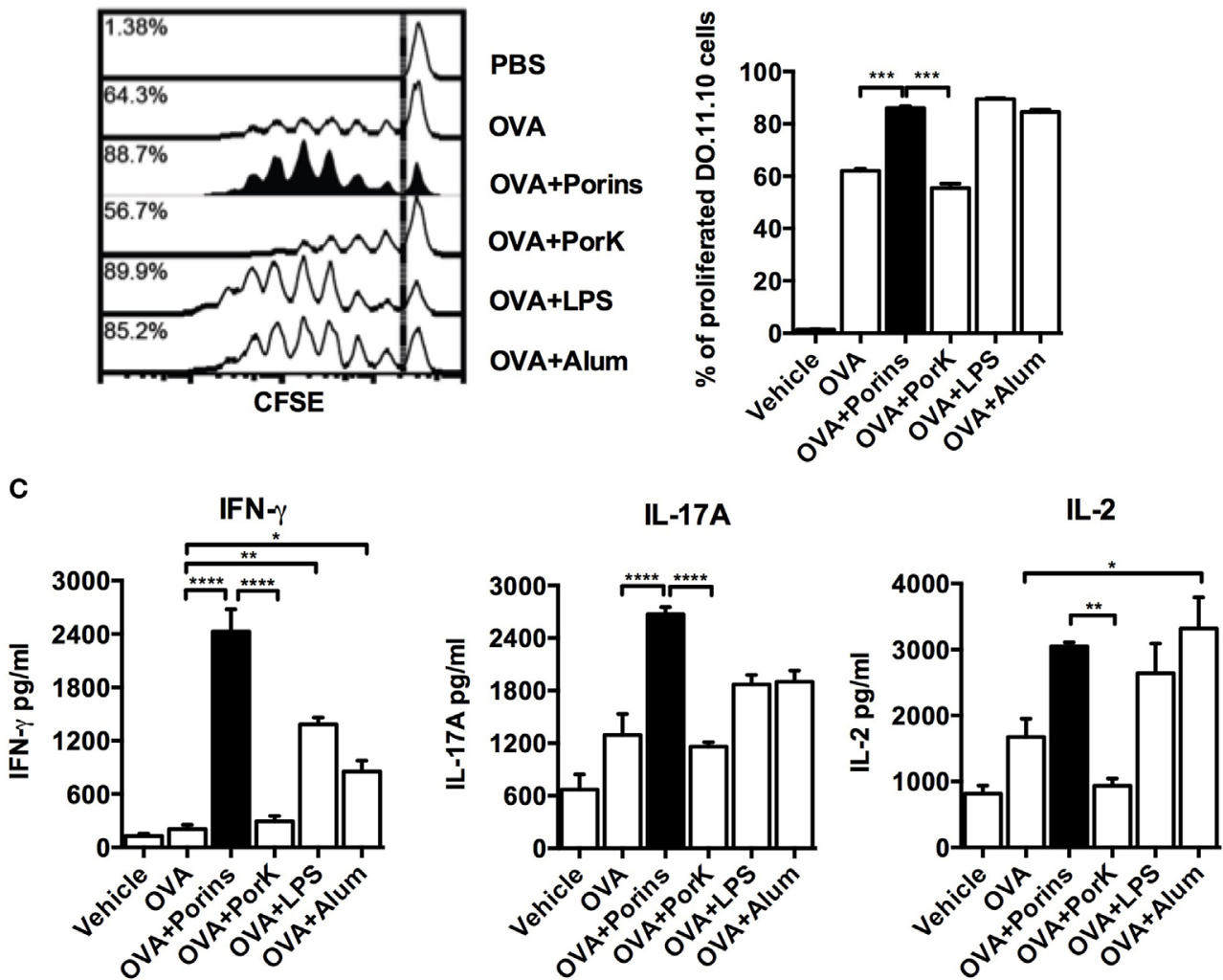

FIGURE 2 Porins from S. Typhi increase cell proliferation and Th1/Th17 cytokine production by ovalbumin (OVA)-specific CD4 ${ }^{+}$T cells. A total of $5 \times 10^{6} \mathrm{CFSE}-l a b e l e d \mathrm{CD} 4^{+} \mathrm{T}$ cells from DO.11.10 mice were transferred to naiive BALB/c mice (4 mice per group) $24 \mathrm{~h}$ prior to s.c. injection into the front footpads with $100 \mu \mathrm{g}$ of OVA, OVA + $10 \mu \mathrm{g}$ of porins, OVA $+10 \mu \mathrm{g}$ of Pork, OVA $+5 \mu \mathrm{g}$ of LPS, or OVA $+100 \mu \mathrm{g}$ of alum. Three days later, in vivo proliferation was assessed as frequency of OVA-specific cells (K1-J26 ${ }^{+}$cells) (A) and CFSE dilution (B). (C) Coculture of purified CD4+ ${ }^{+}$cells from immunized DO.11.10 BALB/C chimeras with OVA-pulsed dendritic cells was performed, supernatants were collected $24 \mathrm{~h}$ later, and cytokines were measured by CBA assay. Mean + SEM are shown. These data are representative of three independent experiments. Statistical analysis was performed using one-way ANOVA with Bonferroni test post hoc. Statistical differences are depicted as ${ }^{\star} P<0.05,{ }^{\star \star} P<0.01,{ }^{\star \star \star} P<0.001$.

were co-immunized with porins and the unconjugated CPS Typhim Vi vaccine, and the antibody responses against Vi CPS were evaluated. The addition of porins resulted in a fourfold increase in $\operatorname{IgM}$ and total IgG antibody titers compared to Vi CPS alone (Figure 4A). Surprisingly, co-immunization with $S$. Typhi porins only induced higher levels of both IgG1 and T-independent associated IgG3 isotype (Figure 4B). These effects of porins on the anti-Vi response were lost following the digestion of porins. Therefore, porins can improve the antibody responses to a TI-2 vaccine antigen.

\section{DISCUSSION}

Vaccination is one of the most efficient strategies to control infectious diseases. Whole inactivated microorganism-based vaccines are highly immunogenic; however, they frequently induce undesired side effects. To diminish this possibility, the development of vaccines has shifted toward the use of purified antigens. However, this strategy carries disadvantages, such as poor immunogenicity of the purified antigen (33). To overcome this problem, the use of adjuvants has been required to potentiate the immune response 


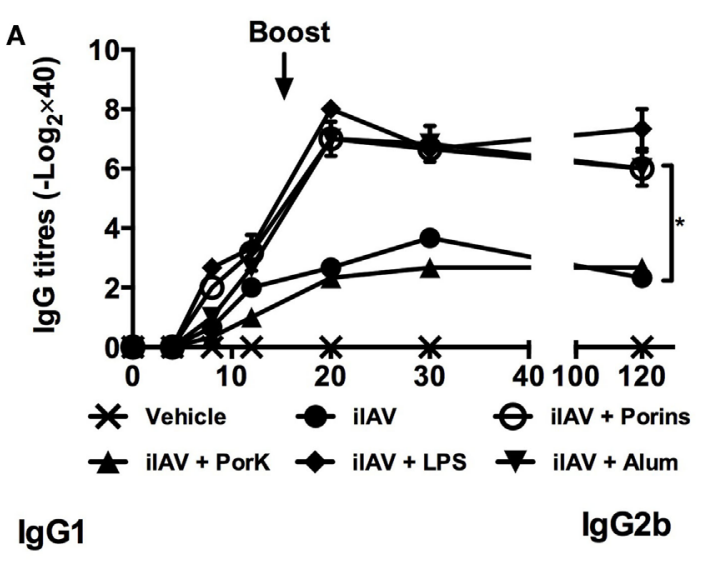

B

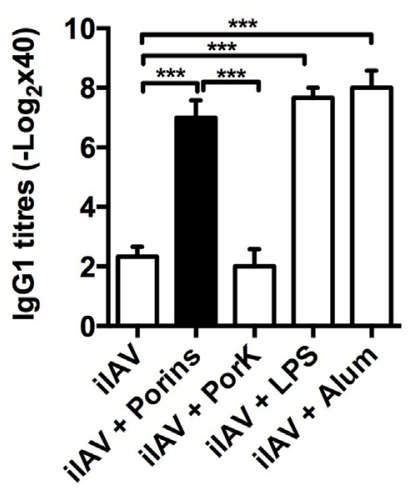

C

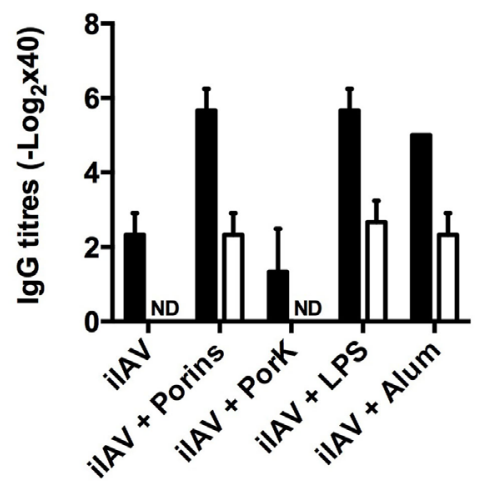

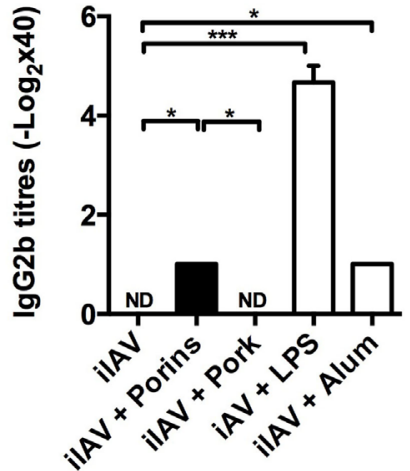

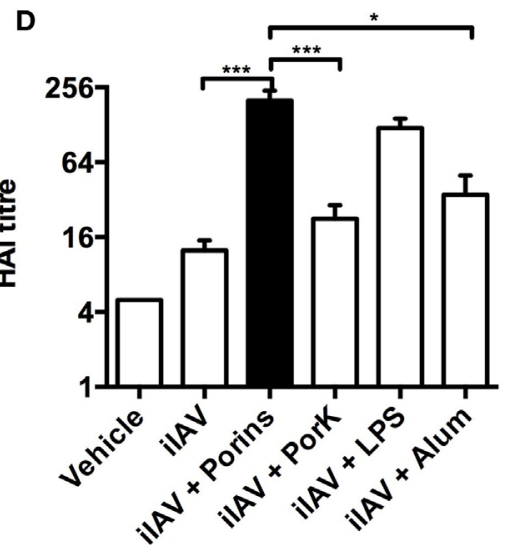

FIGURE 3 | S. Typhi porins enhance functional antibody responses to an inactivated 2009 pandemic influenza vaccine. Four BALB/C mice per group were immunized i.p. with $4 \mathrm{HAU}$ of a pandemic inactivated influenza A virus (ilAV), ilAV $+10 \mu \mathrm{g}$ of porins, ilAV $+10 \mu \mathrm{g}$ of PorK, ilAV $+5 \mu \mathrm{g}$ of LPS, or ilAV $+100 \mu \mathrm{g}$ of alum. (A) Serum IgG antibody responses were measured at the indicated time points. (B) lgG1 and lgG2b, high-avidity lgG titers (C) and HI titers (D) were measured 30 days post-immunization by ELISA. Mean + SEM are plotted. These data are representative of three independent experiments. Statistical analysis was performed using one-way ANOVA with Bonferroni test post hoc. For panel (A), Student's t-test was performed comparing only ovalbumin (OVA) versus OVA + porins groups. Statistical differences are depicted as ${ }^{\star} P<0.05,{ }^{\star \star} P<0.01,{ }^{\star \star \star} P<0.001$.

elicited by vaccination. Although increasing the magnitude of the immune response is essential for an adjuvant, the diversification and persistence of the response are other factors that should also be considered in the development of adjuvants to improve vaccine function (34).

Pattern recognition receptor activation of innate immune cells by adjuvants contributes to their function (35). Our previous studies have shown that $S$. Typhi porins can efficiently activate
APCs and induce the expression of costimulatory molecules and cytokine production through TLR2, TLR4, and MyD88 signaling $(12,14)$. While minor $S$. Typhi porins possess adjuvant properties (14), the adjuvant potential of OmpC and OmpF porins has not been previously assessed.

$S$. Typhi porins enhanced the anti-OVA IgG antibody responses, which is otherwise a poorly immunogenic antigen, to a level comparable the antibody response seen when alum or LPS 


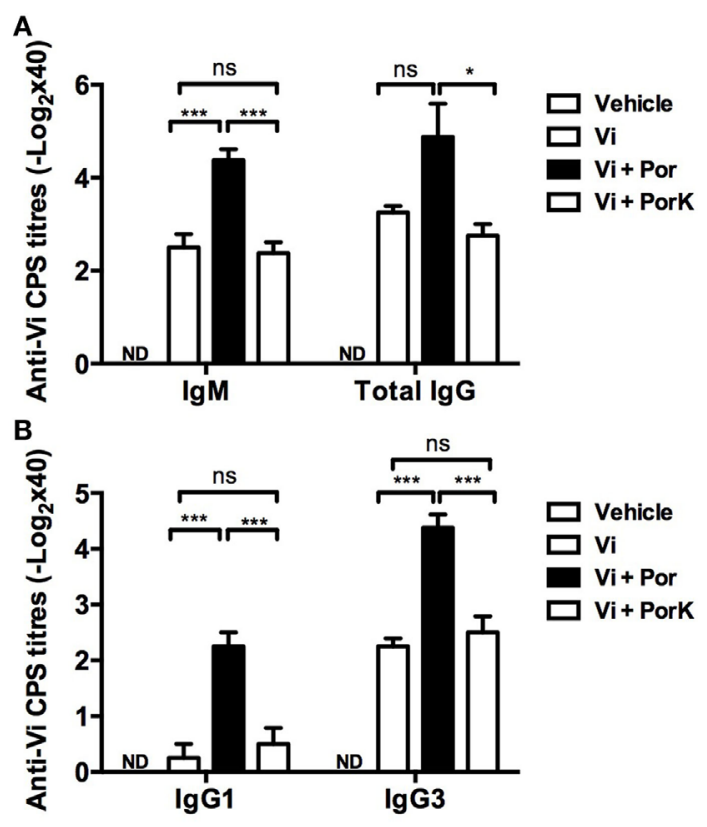

FIGURE 4 | S. Typhi porins promote antibody responses to the T-independent anti-typhoid Vi antigen. Four BALB/c mice per group were immunized i.p. with $10 \mu \mathrm{g}$ of Vi CPS vaccine (Typhim), Vi $+10 \mu \mathrm{g}$ porins or $\mathrm{Vi}+10 \mu \mathrm{g}$ of Pork on days 0 and 15. (A) IgM and total IgG responses and (B) lgG1 and lgG3 responses against Vi CPS were measured by ELISA on day 20 post-immunization. Mean + SEM are plotted. These data are representative of two independent experiments. Statistical analysis was performed using one-way ANOVA with Bonferroni test post hoc. Statistical differences are depicted as ${ }^{\star} P<0.05,{ }^{\star \star} P<0.01,{ }^{* \star \star} P<0.001$.

were added. Other porins have also shown an adjuvant effect on OVA antibody responses $(8,14,36)$, although the persistence of this response has not been well examined in most of these studies. A persistent antibody response lasting several years has been shown in humans after immunization with porins (37). Further studies are needed to examine the nature of this persistent response.

Because long-lasting antibody responses and class switching toward IgG1, IgG2a, and IgG2b are associated with an involvement of T-cells (38) and because we observed that the adjuvant effect of $S$. Typhi porins was abrogated after treatment with an anti-CD4 monoclonal antibody, we analyzed how porins modified $\mathrm{T}$-cell responses. We found that porins enhanced proliferation of OVA-specific $\mathrm{CD}^{+} \mathrm{T}$ cells. In addition, porins co-immunization promoted the production of IFN- $\gamma$, IL-17A, and IL- 2 CD $4^{+}$T cells. This Th1/Th17-associated profile differs from the mixed Th1/Th2 response to the neisserial porin PorB, although this response was only examined in serum (15). Therefore, porins may be useful to modulate the immune response toward a Th1 or Th17 profile, and this property could be useful for vaccines that require Th1 responses to induce protection, such as Mycobacterium tuberculosis or Chlamydia trachomatis vaccines $(39,40)$. In addition, $S$. Typhi porins may enhance responses to vaccines where IL-17 responses are required. Other molecules can also have a Th1/ Th17 promoting effect including CpG (41), poly I:C (42), and glucopyranosyl lipid adjuvant-stable emulsion (GLA-SE) (43) as well as Borrelia burgdorferi outer surface protein A (44) and Brucella abortus outer membrane protein 19 (45).

Porins had a remarkable effect on the response to the inactivated pandemic influenza virus H1N1 2009. Other TLR agonists with adjuvant properties, such as CpG (46), Pam3CSK4 (47), and GLA-SE (48), have been shown to improve the immunogenicity of inactivated influenza vaccines. Interestingly, the induction of HIA titers when major $S$. Typhi porins were included as an adjuvant was superior to the effect induced by alum, supporting the concept that it is not optimal to increase anti-influenza HIA titers (47).

Capsular polysaccharides (CPS), such as S. Typhi Vi, are TI-2 antigens and are B1b antigens in mice (49). Vaccination with such antigens elicits mainly IgM with limited class switching, affinity maturation, and immunological memory (50). Currently, most vaccines based on CPS perform well in healthy adults but have low immunogenicity in infants (51). The Vi CPS vaccine does not induce long-lasting immunity beyond 2 years (52). To overcome such a disadvantage, CPS are typically conjugated to a carrier protein to elicit T-cells and promote IgG switching and memory induction $(52,53)$.

Salmonella Typhi porins could enhance antibody responses to the purified, unconjugated Vi CPS, reflecting a similar finding when minor porins are used (14). Other antigens can also promote IgG responses, including PLc from Vibrio cholerae (54) and other bacterially derived antigens (55). Therefore, the presence of bacterial antigens may naturally augment such responses, possibly by adsorbing the $\mathrm{Vi}$ antigen. Porins can induce protective $\mathrm{B} 1 \mathrm{~b}$ antibody responses to Salmonella (32), and because Vi is also a B1b antigen (49), these effects could be a consequence of the stimulation of B1b cells by porins and Vi antigen. Thus, porins could be used as an adjuvant for TI-2 antigens, such as bacterial capsular polysaccharides.

The mechanism mediating the adjuvant effect might be related to the agonist effect of $S$. Typhi porins on TLR2 and TLR4 (Figure S1 in Supplementary Material). The activation of these receptors by porins might mediate the activation of APCs, such as DCs and macrophages. Activation of APCs then would induce the expression of costimulatory molecules and class II MHC expression and increase antigen presentation, as has been observed in DCs after stimulation or injection with porins $(12,14)$. It could also promote the secretion of pro-inflammatory cytokines, which in turn might activate additional cell populations, including $\mathrm{T}$ cells and B cells. Nevertheless, the effects of porins in B cells as a consequence of direct ligation of TLRs in these cells cannot be discarded, since in a previous report we showed that TLRs on $B$ cells importantly contribute in shaping the antibody responses against porins (12).

Overall, our observations revealed that the adjuvant effect of major S. Typhi porins displayed two patterns. The first pattern indicated that the magnitude and diversity of the response were augmented similar to the model antigen OVA. The second pattern indicated that the diversity of the response elicited by the antigen alone remained unchanged but the magnitude of the response was augmented. This finding could mean that the mechanism underlying the adjuvant effect of porins might vary depending 
on the antigen that is co-immunized. This possibility should be explored further.

The adjuvant effect of porins is similar when compared to LPS; however, LPS cannot be used as adjuvant in animals and human vaccines due to its high toxicity. Contrary to LPS, we have previously shown that porins immunization is safe and well tolerated both for mice and humans $(25,27,28)$; porins, therefore, represent an interesting alternative molecule that can mimic the adjuvant effect of LPS without carrying the same toxicity. Porins also induce, in terms of magnitude and duration of the response, a similar adjuvant effect than alum (the only worldwide used adjuvant in human vaccines). However, when comparing the features of the response induced by porins and alum, some differences can be spotted. For example, in DO.11.10 mice, immunization of porins is more efficient for driving IFN- $\gamma$ and IL-17A-mediated $\mathrm{T}$ cell responses than alum. Likewise, porins induced higher hemagglutination-inhibiting antibody titers than alum when used as adjuvant for influenza virus immunization. Besides, we showed that porins potentiated the antibody responses against an unconjugated, Vi capsular polysaccharide vaccine, whereas alum has shown poor adjuvanticity when used to boost antibody responses against $\mathrm{T}$-independent antigens (56). Taken together, we showed that porins induced a potent adjuvant effect similar to the induced by other well-known molecules with adjuvant properties such as LPS and alum. These results contribute to expand the knowledge about new choices of novel molecules that could be employed to improve vaccines or to develop new ones.

In conclusion, our results show that major $S$. Typhi porins $\mathrm{OmpC}$ and $\mathrm{OmpF}$ have adjuvant properties and potentiate, diversify, and extend B-cell responses to a diverse repertoire of antigens. They function in a manner associated with a Th1/ Th17 profile. Our findings suggest that $S$. Typhi porins represent an additional choice of vaccine adjuvant for T-dependent and T-independent antigens.

\section{REFERENCES}

1. Toussi DN, Massari P. Immune adjuvant effect of molecularly-defined toll-like receptor ligands. Vaccines (Basel) (2014) 2(2):323-53. doi:10.3390/ vaccines 2020323

2. Galdiero S, Falanga A, Cantisani M, Tarallo R, Della Pepa ME, D'Oriano $\mathrm{V}$, et al. Microbe-host interactions: structure and role of Gramnegative bacterial porins. Curr Protein Pept Sci (2012) 13(8):843-54. doi:10.2174/138920312804871120

3. Massari P, Ram S, Macleod H, Wetzler LM. The role of porins in neisserial pathogenesis and immunity. Trends Microbiol (2003) 11(2):87-93. doi:10.1016/ S0966-842X(02)00037-9

4. Nikaido H. Molecular basis of bacterial outer membrane permeability revisited. Microbiol Mol Biol Rev (2003) 67(4):593-656. doi:10.1128/ MMBR.67.4.593-656.2003

5. Wetzler LM. Innate immune function of the neisserial porins and the relationship to vaccine adjuvant activity. Future Microbiol (2010) 5(5):749-58. doi:10.2217/fmb.10.41

6. Galdiero M, Galdiero M, Finamore E, Rossano F, Gambuzza M, Catania MR, et al. Haemophilus influenzae porin induces toll-like receptor 2-mediated cytokine production in human monocytes and mouse macrophages. Infect Immun (2004) 72(2):1204-9. doi:10.1128/IAI.72.2.1204-1209.2004

7. Marcatili A, D’Isanto M, Galdiero M, Pagnini U, Palomba E, Vitiello M, et al. Role of Pasteurella multocida, Pasteurella haemolytica and Salmonella typhimurium porins on inducible nitric oxide release by murine macrophages. Res Microbiol (2000) 151(3):217-28. doi:10.1016/S0923-2508(00)00142-X

\section{AUTHOR CONTRIBUTIONS}

MP-T performed the experiments, analyzed the results, and wrote the paper; NV-P and RP-P analyzed the results and wrote the paper; CG-C, CP-S, and MM-E designed the experiments and analyzed the results; IB and SP-T provided the reagents; LA-P, $\mathrm{AC}$, and $\mathrm{AI}$ analyzed the results and revised the manuscript; and LB and CL-M designed the study, supervised the experiments, and revised the manuscript.

\section{ACKNOWLEDGMENTS}

The authors wish to acknowledge technical assistance from Emiliano Hisaki and Pablo A. Vieyra-García and wish to thank Mr. Ricardo Vargas Orozco and Daniel Sánchez Almaraz, DVM, for their valuable support and mouse care at the animal facilities of the Experimental Medicine Department, Faculty of Medicine, UNAM.

\section{FUNDING}

The study was funded by a grant from the Mexican National Council for Science and Technology (CONACyT) project number CB-2015-256402. The study was also funded by IMSS funding project number FIS/IMSS/PROT/G15/1438 awarded to CL-M and by a CONACYT project number CB-2011-166946 awarded to RP-P.

\section{SUPPLEMENTARY MATERIAL}

The Supplementary Material for this article can be found online at http://journal.frontiersin.org/article/10.3389/fimmu. 2017.00230/full\#supplementary-material.

8. Toussi DN, Liu X, Massari P. The FomA porin from Fusobacterium nucleatum is a toll-like receptor 2 agonist with immune adjuvant activity. Clin Vaccine Immunol (2012) 19(7):1093-101. doi:10.1128/CVI.00236-12

9. Biswas A, Banerjee P, Mukherjee G, Biswas T. Porin of Shigella dysenteriae activates mouse peritoneal macrophage through toll-like receptors 2 and 6 to induce polarized type I response. Mol Immunol (2007) 44(5):812-20. doi:10.1016/j.molimm.2006.04.007

10. Bhowmick R, Pore D, Chakrabarti MK. Outer membrane protein A (OmpA) of Shigella flexneri 2a induces TLR2-mediated activation of B cells: involvement of protein tyrosine kinase, ERK and NF-kappaB. PLoS One (2014) 9(10):e109107. doi:10.1371/journal.pone.0109107

11. Galdiero M,Pisciotta MG, Galdiero E, CarratelliCR. Porins andlipopolysaccharide from Salmonella typhimurium regulate the expression of CD80 and CD86 molecules on B cells and macrophages but not CD28 and CD152 on T cells. Clin Microbiol Infect (2003) 9(11):1104-11. doi:10.1046/j.1469-0691.2003.00728.x

12. Cervantes-Barragan L, Gil-Cruz C, Pastelin-Palacios R, Lang KS, Isibasi A, Ludewig B, et al. TLR2 and TLR4 signaling shapes specific antibody responses to Salmonella typhi antigens. Eur J Immunol (2009) 39(1):126-35. doi:10.1002/ eji.200838185

13. Lee JS, Jung ID, Lee CM, Park JW, Chun SH, Jeong SK, et al. Outer membrane protein a of Salmonella enterica serovar typhimurium activates dendritic cells and enhances Th1 polarization. BMC Microbiol (2010) 10:263. doi:10.1186/1471-2180-10-263

14. Moreno-Eutimio MA, Tenorio-Calvo A, Pastelin-Palacios R, PerezShibayama C, Gil-Cruz C, Lopez-Santiago R, et al. Salmonella typhi OmpS1 and OmpS2 porins are potent protective immunogens with 
adjuvant properties. Immunology (2013) 139(4):459-71. doi:10.1111/ imm. 12093

15. Liu X, Wetzler LM, Massari P. The PorB porin from commensal Neisseria lactamica induces $T h 1$ and Th2 immune responses to ovalbumin in mice and is a potential immune adjuvant. Vaccine (2008) 26(6):786-96. doi:10.1016/j. vaccine.2007.11.080

16. Wetzler LM, Ho Y, Reiser H. Neisserial porins induce B lymphocytes to express costimulatory B7-2 molecules and to proliferate. J Exp Med (1996) 183(3):1151-9. doi:10.1084/jem.183.3.1151

17. Singleton TE, Massari P, Wetzler LM. Neisserial porin-induced dendritic cell activation is MyD88 and TLR2 dependent. J Immunol (2005) 174(6):3545-50. doi:10.4049/jimmunol.174.6.3545

18. Massari P, Visintin A, Gunawardana J, Halmen KA, King CA, Golenbock DT, et al. Meningococcal porin PorB binds to TLR2 and requires TLR1 for signaling. J Immunol (2006) 176(4):2373-80. doi:10.4049/jimmunol.176.4.2373

19. Puente JL, Flores V, Fernandez M, Fuchs Y, Calva E. Isolation of an ompC-like outer membrane protein gene from Salmonella typhi. Gene (1987) 61(1):75-83. doi:10.1016/0378-1119(87)90366-0

20. Fernandez-Mora M, Oropeza R, Puente JL, Calva E. Isolation and characterization of ompS1, a novel Salmonella typhi outer membrane protein-encoding gene. Gene (1995) 158(1):67-72. doi:10.1016/0378-1119(95)00171-2

21. Fernandez-Mora M, Puente JL, Calva E. OmpR and LeuO positively regulate the Salmonella enterica serovar Typhi ompS2 porin gene. J Bacteriol (2004) 186(10):2909-20. doi:10.1128/JB.186.10.2909-2920.2004

22. Rodriguez-Morales O, Fernandez-Mora M, Hernandez-Lucas I, Vazquez A, Puente JL, Calva E. Salmonella enterica serovar typhimurium ompS1 and ompS2 mutants are attenuated for virulence in mice. Infect Immun (2006) 74(2):1398-402. doi:10.1128/IAI.74.2.1398-1402.2006

23. De la Cruz MA, Calva E. The complexities of porin genetic regulation. J Mol Microbiol Biotechnol (2010) 18(1):24-36. doi:10.1159/000274309

24. Isibasi A, Ortiz V, Vargas M, Paniagua J, Gonzalez C, Moreno J, et al. Protection against Salmonella typhi infection in mice after immunization with outer membrane proteins isolated from Salmonella typhi 9,12,d, Vi. Infect Immun (1988) 56(11):2953-9.

25. Isibasi A, Ortiz-Navarrete V, Paniagua J, Pelayo R, Gonzalez CR, Garcia JA, et al. Active protection of mice against Salmonella typhi by immunization with strain-specific porins. Vaccine (1992) 10(12):811-3. doi:10.1016/0264-410X(92)90041-H

26. Isibasi A, Paniagua J, Rojo MP, Martin N, Ramirez G, Gonzalez CR, et al. Role of porins from Salmonella typhi in the induction of protective immunity. Ann N Y Acad Sci (1994) 730:350-2. doi:10.1111/j.1749-6632.1994.tb44289.x

27. Salazar-Gonzalez RM, Maldonado-Bernal C, Ramirez-Cruz NE, Rios-Sarabia N, Beltran-Nava J, Castanon-Gonzalez J, et al. Induction of cellular immune response and anti-Salmonella enterica serovar typhi bactericidal antibodies in healthy volunteers by immunization with a vaccine candidate against typhoid fever. Immunol Lett (2004) 93(2-3):115-22. doi:10.1016/j.imlet.2004.01.010

28. Secundino I, Lopez-Macias C, Cervantes-Barragan L, Gil-Cruz C, RiosSarabia N, Pastelin-Palacios R, et al. Salmonella porins induce a sustained, lifelong specific bactericidal antibody memory response. Immunology (2006) 117(1):59-70. doi:10.1111/j.1365-2567.2005.02263.x

29. Shaw ML, Stone KL, Colangelo CM, Gulcicek EE, Palese P. Cellular proteins in influenza virus particles. PLoS Pathog (2008) 4(6):e1000085. doi:10.1371/ journal.ppat. 1000085

30. Delgado MF, Coviello S, Monsalvo AC, Melendi GA, Hernandez JZ, Batalle JP, et al. Lack of antibody affinity maturation due to poor toll-like receptor stimulation leads to enhanced respiratory syncytial virus disease. Nat Med (2009) 15(1):34-41. doi:10.1038/nm.1894

31. King C. New insights into the differentiation and function of $T$ follicular helper cells. Nat Rev Immunol (2009) 9(11):757-66. doi:10.1038/nri2644

32. Gil-Cruz C, Bobat S, Marshall JL, Kingsley RA, Ross EA, Henderson IR, et al. The porin OmpD from nontyphoidal Salmonella is a key target for a protective B1b cell antibody response. Proc Natl Acad Sci U S A (2009) 106(24):9803-8. doi:10.1073/pnas.0812431106

33. Oleszycka E, Lavelle EC. Immunomodulatory properties of the vaccine adjuvant alum. Curr Opin Immunol (2014) 28:1-5. doi:10.1016/j.coi.2013.12.007

34. Coffman RL, Sher A, Seder RA. Vaccine adjuvants: putting innate immunity to work. Immunity (2010) 33(4):492-503. doi:10.1016/j.immuni.2010.10.002
35. Iwasaki A, Medzhitov R. Control of adaptive immunity by the innate immune system. Nat Immunol (2015) 16(4):343-53. doi:10.1038/ni.3123

36. Platt A, MacLeod H, Massari P, Liu X, Wetzler L. In vivo and in vitro characterization of the immune stimulating activity of the Neisserial porin PorB. PLoS One (2013) 8(12):e82171. doi:10.1371/journal.pone.0082171

37. Perez-Shibayama C, Gil-Cruz C, Pastelin-Palacios R, Cervantes-Barragan L, Hisaki E, Chai Q, et al. IFN-gamma-producing CD4+ T cells promote generation of protective germinal center-derived IgM+ B cell memory against Salmonella typhi. J Immunol (2014) 192(11):5192-200. doi:10.4049/ jimmunol.1302526

38. Reinhardt RL, Liang HE, Locksley RM. Cytokine-secreting follicular T cells shape the antibody repertoire. Nat Immunol (2009) 10(4):385-93. doi:10.1038/ ni. 1715

39. de Jong R, Altare F, Haagen IA, Elferink DG, Boer T, van Breda Vriesman PJ, et al. Severe mycobacterial and Salmonella infections in interleukin-12 receptor-deficient patients. Science (1998) 280(5368):1435-8. doi:10.1126/ science.280.5368.1435

40. Jouanguy E, Doffinger R, Dupuis S, Pallier A, Altare F, Casanova JL. IL-12 and IFN-gamma in host defense against mycobacteria and Salmonella in mice and men. Curr Opin Immunol (1999) 11(3):346-51. doi:10.1016/ S0952-7915(99)80055-7

41. Mori A, Oleszycka E, Sharp FA, Coleman M, Ozasa Y, Singh M, et al. The vaccine adjuvant alum inhibits IL-12 by promoting PI3 kinase signaling while chitosan does not inhibit IL-12 and enhances Th1 and Th17 responses. Eur J Immunol (2012) 42(10):2709-19. doi:10.1002/ eji.201242372

42. Longhi MP, Trumpfheller C, Idoyaga J, Caskey M, Matos I, Kluger C, et al. Dendritic cells require a systemic type I interferon response to mature and induce CD4+ Th1 immunity with poly IC as adjuvant. J Exp Med (2009) 206(7):1589-602. doi:10.1084/jem.20090247

43. Dubois Cauwelaert N, Desbien AL, Hudson TE, Pine SO, Reed SG, Coler $\mathrm{RN}$, et al. The TLR4 agonist vaccine adjuvant, GLA-SE, requires canonical and atypical mechanisms of action for TH1 induction. PLoS One (2016) 11(1):e0146372. doi:10.1371/journal.pone.0146372

44. Pal S, Luke CJ, Barbour AG, Peterson EM, de la Maza LM. Immunization with the Chlamydia trachomatis major outer membrane protein, using the outer surface protein A of Borrelia burgdorferi as an adjuvant, can induce protection against a chlamydial genital challenge. Vaccine (2003) 21(13-14):1455-65. doi:10.1016/S0264-410X(02)00680-1

45. Coria LM, Ibanez AE, Pasquevich KA, Cobiello PL, Frank FM, Giambartolomei $\mathrm{GH}$, et al. Brucella abortus Omp19 recombinant protein subcutaneously co-delivered with an antigen enhances antigen-specific $\mathrm{T}$ helper 1 memory responses and induces protection against parasite challenge. Vaccine (2016) 34(4):430-7. doi:10.1016/j.vaccine.2015.12.012

46. Moldoveanu Z, Love-Homan L, Huang WQ, Krieg AM. CpG DNA, a novel immune enhancer for systemic and mucosal immunization with influenza virus. Vaccine (1998) 16(11-12):1216-24. doi:10.1016/ S0264-410X(98)80122-9

47. Caproni E, Tritto E, Cortese M, Muzzi A, Mosca F, Monaci E, et al. MF59 and Pam3CSK4 boost adaptive responses to influenza subunit vaccine through an IFN type I-independent mechanism of action. J Immunol (2012) 188(7):3088-98. doi:10.4049/jimmunol.1101764

48. Coler RN, Baldwin SL, Shaverdian N, Bertholet S, Reed SJ, Raman VS, et al. A synthetic adjuvant to enhance and expand immune responses to influenza vaccines. PLoS One (2010) 5(10):e13677. doi:10.1371/journal.pone.0013677

49. Marshall JL, Flores-Langarica A, Kingsley RA, Hitchcock JR, Ross EA, Lopez-Macias C, et al. The capsular polysaccharide Vi from Salmonella typhi is a B1b antigen. JImmunol (2012) 189(12):5527-32. doi:10.4049/ jimmunol.1103166

50. Jakobsen H, Jonsdottir I. Mucosal vaccination against encapsulated respiratory bacteria - new potentials for conjugate vaccines? Scand J Immunol (2003) 58(2):119-28. doi:10.1046/j.1365-3083.2003.01292.x

51. Pollard AJ, Perrett KP, Beverley PC. Maintaining protection against invasive bacteria with protein-polysaccharide conjugate vaccines. Nat Rev Immunol (2009) 9(3):213-20. doi:10.1038/nri2494

52. Anwar E, Goldberg E, Fraser A, Acosta CJ, Paul M, Leibovici L. Vaccines for preventing typhoid fever. Cochrane Database Syst Rev (2014) 1:CD001261. doi:10.1002/14651858.CD001261.pub3 
53. Poland GA. Prevention of meningococcal disease: current use of polysaccharide and conjugate vaccines. Clin Infect Dis (2010) 50(Suppl 2):S45-53. doi:10.1086/648964

54. Acevedo R, Callico A, Aranguren Y, Zayas C, Valdes Y, Perez O, et al. Immune adjuvant effect of $V$. cholerae $\mathrm{O} 1$ derived proteoliposome coadministered by intranasal route with Vi polysaccharide from Salmonella typhi. BMC Immunol (2013) 14(Suppl 1):S10. doi:10.1186/1471-2172-14-S1-S10

55. Romeu B, Lastre M, Reyes L, Gonzalez E, Borrero Y, Lescaille D, et al. Nasal immunization of mice with AFCo1 or AFPL1 plus capsular polysaccharide Vi from Salmonella typhi induces cellular response and memory $\mathrm{B}$ and $\mathrm{T}$ cell responses. Vaccine (2014) 32(51):6971-8. doi:10.1016/j. vaccine.2014.10.037

56. Flebbe LM, Braley-Mullen H. Immunopotentiating effects of the adjuvants SGP and Quil A. I. Antibody responses to T-dependent and T-independent antigens. Cell Immunol (1986) 99(1):119-27. doi:10.1016/0008-8749(86)90221-2
Disclaimer: The results of this work have led to Salmonella Typhi OmpC and OmpF porins being patented to use them as adjuvants for vaccines.

Conflict of Interest Statement: The authors declare that the research was conducted in the absence of any commercial or financial relationships that could be construed as a potential conflict of interest.

Copyright $\odot 2017$ Pérez-Toledo, Valero-Pacheco, Pastelin-Palacios, Gil-Cruz, PerezShibayama, Moreno-Eutimio, Becker, Pérez-Tapia, Arriaga-Pizano, Cunningham, Isibasi, Bonifaz and López-Macias. This is an open-access article distributed under the terms of the Creative Commons Attribution License (CC BY). The use, distribution or reproduction in other forums is permitted, provided the original author(s) or licensor are credited and that the original publication in this journal is cited, in accordance with accepted academic practice. No use, distribution or reproduction is permitted which does not comply with these terms. 